Portland State University

PDXScholar

\title{
A Retrospective Chart Review of Sleep Questionnaires in Children with Down Syndrome
}

Sarah Therese Florig

Portland State University

Follow this and additional works at: https://pdxscholar.library.pdx.edu/honorstheses

Let us know how access to this document benefits you.

\section{Recommended Citation}

Florig, Sarah Therese, "A Retrospective Chart Review of Sleep Questionnaires in Children with Down Syndrome" (2019). University Honors Theses. Paper 742.

https://doi.org/10.15760/honors.759

This Thesis is brought to you for free and open access. It has been accepted for inclusion in University Honors Theses by an authorized administrator of PDXScholar. Please contact us if we can make this document more accessible: pdxscholar@pdx.edu. 


\section{A Retrospective Chart Review of Sleep Questionnaires in Children with Down Syndrome}

by

Sarah Therese Florig

An undergraduate honors thesis submitted in partial fulfillment of the requirements for the degree of

Bachelor of Science

in

University Honors

and

Heath Studies: Health Science

Thesis Adviser

Derek J. Lam, MD, MPH

Oregon Health \& Science University

Portland State University

in collaboration with

Oregon Health and Science University 


\begin{abstract}
Introduction: Despite the high prevalence of obstructive sleep apnea (OSA) in children with Down syndrome (DS), very few subjective pediatric assessments have been evaluated in this population. The Sleep-Related Breathing Disorder subscale of the Pediatric Sleep Questionnaire (SRBD-PSQ) and Obstructive Sleep Apnea-18 Quality-of-Life Questionnaire (OSA-18) are two sleep-related questionnaires previously validated for the general pediatric population. Our aim was to assess the performance of these questionnaires in our DS population.
\end{abstract}

Methods: We performed a retrospective case series of patients with DS, ages 2-18 years, seen in our tertiary care DS clinic between May 1, 2009 and October 1, 2018. We included those who returned complete sleep questionnaires and had polysomnography testing within the same year. Patients were excluded for history of OSA or lack of questionnaire data. A Student's t-test was used to compare mean SRBD-PSQ total score to published norms. Spearman correlation coefficients were calculated between obstructive apnea-hypopnea index (oAHI) and SRBD-PSQ or OSA-18 total scores, as well as domain scores.

Results: SRBD-PSQ $(\mathrm{N}=50)$ and OSA-18 $(\mathrm{N}=36)$ average total scores were $0.46 \pm 0.20$ and $55.47 \pm 22.9$, respectively. OSA-18 total score was better correlated with oAHI $\left(\mathrm{r}_{\mathrm{s}}=0.46, \mathrm{p}<\right.$ 0.05) than SRBD-PSQ $\left(r_{s}=0.23, p>0.05\right)$. Questionnaire scores seemed to be most strongly, positively correlated with oAHI in adolescents and negatively correlated in children.

Conclusion: The SRBD-PSQ and OSA-18 demonstrated weak to moderate correlations with oAHI, but scores within domains of each questionnaire showed varying strengths of correlation with polysomnography. Further study is needed to better define how these questionnaires should be used and interpreted in the DS population. 


\section{Keywords}

Children; Down syndrome; Obstructive sleep apnea; Pediatric sleep questionnaire; Quality-of-life questionnaire

\section{Funding}

Work reported in this publication was supported in part by the National Institutes of Health Common Fund and Office of Scientific Workforce Diversity under three awards:

UL1GM118964, RL5GM118963 and TL4GM118965. Administered by the National Institute of General Medical Sciences. This work is solely the responsibility of the authors and does not necessarily represent the official view of the National Institutes of Health. Research reported in this publication was also supported by the National Heart, Lung and Blood Institute of the National Institutes of Health under award K23HL127132. 


\section{Acknowledgments}

I would like to acknowledge and thank my advisor, Dr. Derek Lam, for his mentorship, guidance and support throughout the writing of this thesis and our work together. I'm deeply indebted to him for his time and contributions made to this paper. I would also like to thank Dr. Jill Sanford and Dr. Joseph Pinter for their time and support sharing their research database, which was utilize for this project. I am greatly thankful for their knowledge and expertise in helping me complete this work. I would also like to extend my deepest gratitude to Dr. Dara Shifrer for taking me under her wing and mentoring me in my future career as an analyst. Her teaching provided me with the skills to take on the task of performing the data analytics necessary for this thesis.

I would like to like to recognize my parents, David Florig and Caryn Tierney, for loving me unconditionally and setting strong examples that have taught me to work hard for the things that I aspire to achieve. Thank you for encouraging me and providing me with the opportunity to engage in this project. I want to thank Genevieve Florig for a sister's emotional support, intellectual stimulation and much needed distractions from school. I am inspired to pursue an unconventional dream in which I truly believe. So, thank you, to Dad, Mom and Sis for being the most supportive family one could hope for. Finally, this work wouldn't have been completed without the dedication of my partner, Austin and his family. They have been a constant source of support and encouragement during the challenges of my academic endeavors and life pursuits. I am truly thankful for having all of you in my life. 


\section{Table of Contents}

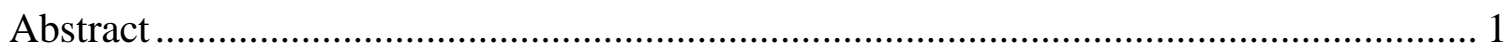

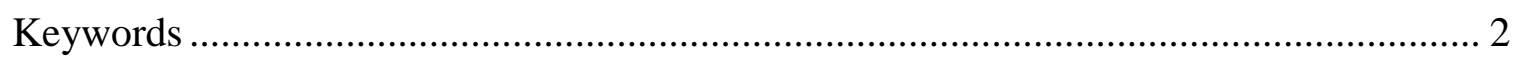

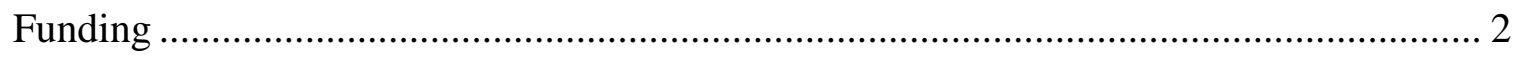

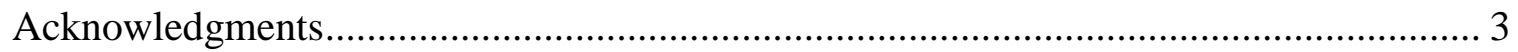

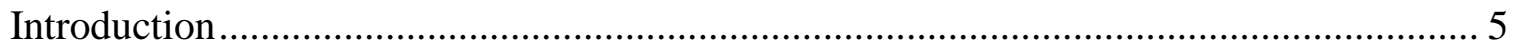

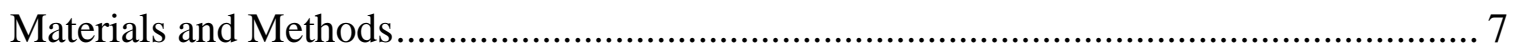

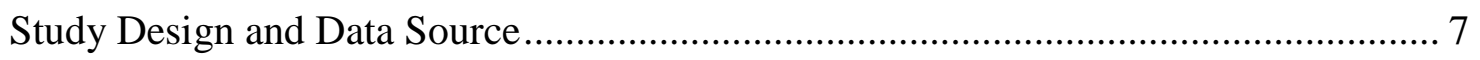

Comorbidities and Outcome Measures .................................................................. 7

Sleep-Related Breathing Disorders Scale of the Pediatric Sleep Questionnaire (SRBD-

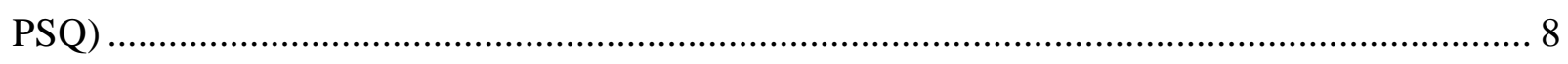

Obstructive Sleep Apnea-18 Quality-of-Life Questionnaire (OSA-18) ...................... 8

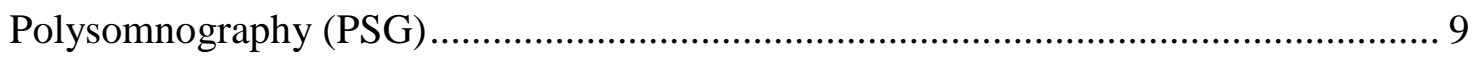

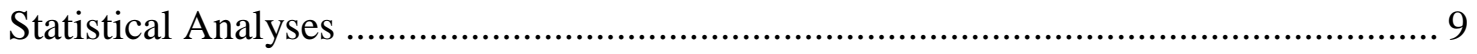

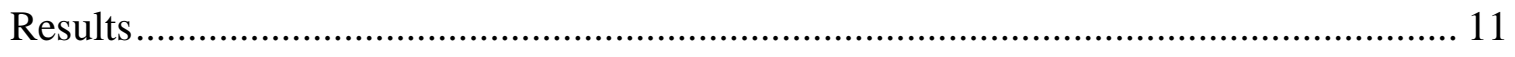

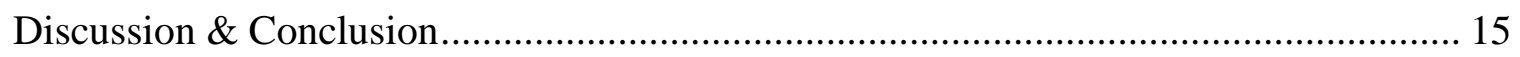

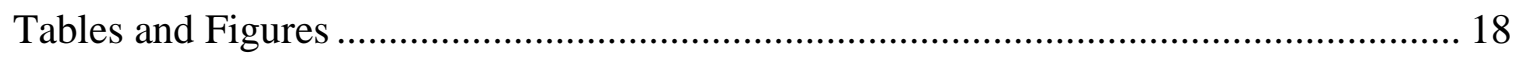

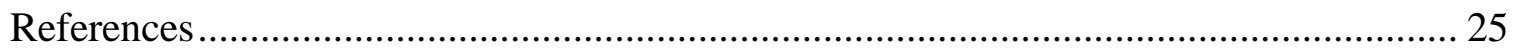




\section{Introduction}

Despite frequent parental reports of symptoms of sleep-related breathing disorders in children with Down syndrome (DS), very few validated subjective pediatric assessments for obstructive sleep apnea (OSA) have been investigated in this population. This is important because gold standard screening via polysomnography (PSG) is often burdensome to families and standardized alternatives are needed in this population. ${ }^{1}$ The purpose of this study was to investigate the function of the Sleep-Related Breathing Disorder subscale of the Pediatric Sleep Questionnaire (SRBD-PSQ) and Obstructive Sleep Apnea-18 Quality-of-Life Questionnaire (OSA-18) in assessment for OSA in children with Down syndrome.

OSA is defined as a sleep-related breathing disorder characterized by partial or complete airway obstruction that occurs in an intermittent or prolonged manner, disrupting both normal ventilation during sleep and sleep patterns. ${ }^{2}$ Previous studies have demonstrated that OSA is highly prevalent in children with DS, relative to the general pediatric population. ${ }^{3,4}$ Additionally, untreated OSA has been associated with a great number of adverse neurocognitive, cardiovascular and metabolic sequelae in children. ${ }^{5-7}$ Because of this, the American Academy of Pediatrics recommends screening all children with DS for OSA by the age of four. ${ }^{8}$ Polysomnography (PSG) remains the gold standard objective measurement for screening and diagnosing childhood OSA. ${ }^{9}$ Unfortunately, patients and families often face barriers to the laborintensive nature of overnight PSG testing and it remains unsuitable for routine screening of OSA in pediatric clinical practice. ${ }^{1}$ Given the need for prompt recognition of OSA in the pediatric population, sleep questionnaires have been proposed as an alternative tool when evaluating patients. ${ }^{10,11}$ 
Despite the wide availability and use of these questionnaires in the general pediatric population, minimal investigation has been done to study how these questionnaires may function in the DS population. ${ }^{12}$ The SRBD-PSQ and OSA-18 are two examples of general pediatric sleep questionnaires that have been studied and validated for use in children. ${ }^{12-14}$ The SRBD-PSQ serves to screen for the presence of OSA, while the OSA-18 serves as a tool to evaluate sleeprelated quality of life. Studying how they perform in children with DS is important because both the SRBD-PSQ and OSA-18 incorporate domains that address behavioral elements. When parents respond to these questions for children with developmental disorders, the child may score positively on some these items, independent to the presence of OSA. Additionally, the SRBDPSQ contains questions regarding reduced growth rate, weight gain and nighttime uresis, all of which are frequently observed in children with DS and again may occur regardless of the presence of OSA. ${ }^{15,16}$ Given the previously demonstrated reliability and convenience of pediatric sleep questionnaires to identify those at risk for OSA and the high probability of OSA in the DS population, this study aimed to investigate the performance of the SRBD-PSQ and OSA-18 in our DS population. 


\section{Materials and Methods}

\section{Study Design and Data Source}

This study was a retrospective case series that examined records from the Down Syndrome Clinic at Doernbecher Children's Hospital, a tertiary-care center. We collected data for patients referred to the Down Syndrome Clinic between May 1, 2009 and October 1, 2018. Children with Down Syndrome (DS), between 2 and 18 years of age, who completed the SleepRelated Breathing Disorders Scale of the Pediatric Sleep Questionnaire (SRBD-PSQ) and/or Obstructive Sleep Apnea-18 Quality-of-Life Questionnaire (OSA-18) and had undergone at least one overnight polysomnography (PSG) within one year of returning the completed questionnaire(s) were included in the study. Children missing both questionnaires, or with a documented history of tracheostomy or previous treatment for obstructive sleep apnea (OSA) were excluded.

We abstracted electronic medical record data (Epic Systems Corporations, Verona, Wisconsin) from identified study participants. This included demographic data (i.e. date of birth, age, gender, height, weight, body mass index [BMI] and BMI percentile), history of OSA and other comorbidities, OSA treatment history, SRBD-PSQ and OSA-18 questionnaires and polysomnography data. This study was approved by the Institutional Review Board of Oregon Health \& Science University.

\section{Comorbidities and Outcome Measures}

Age of the child was calculated using the date of completion of the SRBD-PSQ or OSA18. The sample was stratified into three age ranges: preschool (age 2 to 3 years), child (age 5 to 11 years) and adolescent (age 12 to 18 years). Gender was categorized male or female, based on sex at birth. BMI was calculated using height and weight measurements taken at their 
polysomnography appointment (when available) or a relevant clinic visit when the questionnaire(s) was returned. BMI percentile, for age, was calculated based on normative data published by Centers for Disease Control and Prevention. ${ }^{17}$ Obesity was defined as a BMI percentile $>95$ and was also dichotomized as present or absent. ${ }^{9}$

Sleep-Related Breathing Disorders Scale of the Pediatric Sleep Questionnaire (SRBD-PSQ)

The SRBD-PSQ is composed of 22 questions, which ask parents or caregivers to respond "Yes", "No" or "Don't know" (Table 1). ${ }^{14}$ The questionnaire contains three sleep-related domains: snoring, sleepiness and behavior. SRBD-PSQ total scores were calculated by dividing the total number of positive item responses ("Yes") by the sum of the total number of positive and negative responses ("Yes" + "No"). Domain scores were calculated in the same manner, using only items within the specific domain being calculated. A total score greater than or equal to 0.33 is considered a positive screen, suggesting the child is at a high risk for OSA. These values are based on results of a previously published validation study in the general pediatric population, which produced a sensitivity of 0.83 and a specificity of $0.87 .{ }^{15}$ Total and domain scores were calculated, as stated above, and treated as continuous variables for analysis. Obstructive Sleep Apnea-18 Quality-of-Life Questionnaire (OSA-18)

The OSA-18 contains 18 items, within which are five sleep-related domains: sleep disturbance, physical symptoms, emotional distress, daytime function and caregiver concerns (Table 2) ${ }^{13}$ Parents or caregivers are asked to respond to each question on how often their child experienced each symptom in the last four weeks through a 7-point Likert scale rating including: (1) "None of the time", (2) "Hardly any of the time", (3) "A little of the time", (4) "Some of the time", (5) "A good bit of the time", (6) "Most of the time" and (7) "All of the time". Individual item scores are summed to return a total score, ranging from 18-126, that measures the overall 
impact of OSA on a child's sleep-related quality of life. Domain scores are calculated by summing the responses of the items within each given domain. Total score measures overall impact of OSA on a child's sleep-related quality of life, where less than 60 suggests a small impact, between 60 and 80 suggests moderate impact and greater than 80 suggests a severe impact. ${ }^{13}$ For this analysis, the total and domain scores were calculated, as specified here, and treated as continuous variables.

Polysomnography (PSG)

Overnight attended PSG is the gold standard for diagnosis of OSA. ${ }^{2,8,9}$ It consists of several measurements of cardiorespiratory status including oronasal airflow, oxyhemoglobin saturation $\left(\mathrm{SpO}_{2}\right)$, end-tidal carbon dioxide $\left(\mathrm{CO}_{2}\right)$, electrocardiogram and pulse rate. ${ }^{1}$ For the purpose of this study, the output parameter used to characterize the severity of OSA was the

obstructive apnea-hypopnea index (oAHI), measured in respiratory events per hour. ${ }^{2,9}$ The oAHI was calculated by summing the number of hypopnea events (reductions in airflow) and obstructive apnea events (cessations in airflow) and dividing this by the total sleep time (in hours). Data was included for all individuals who had PSG testing appointments that fell within a one-year period from the time at which the questionnaire was returned. In analysis, oAHI was treated as a continuous variable.

\section{Statistical Analyses}

Descriptive statistics are provided for all individuals who obtained PSG testing within one year of returning a completed SRBD-PSQ or OSA-18 (Table 3.a. and Table 3.b., respectively). Summaries are given for the overall sample and then for each age-range following stratification. Values are reported as mean, standard deviation (SD) and range for continuous variables or number of patients (percent) for categorical variables. Student's t-test was used to 
compare the SRBD-PSQ total score to published norms of $0.31 \pm 0.21 .{ }^{14}$ Correlations between SRBD-PSQ total score and oAHI, SRBD-PSQ domain scores and oAHI, OSA-18 total scores and oAHI or OSA-18 domain scores and oAHI were assessed using Spearman's correlation coefficient (Table 4.a. \& 4.b. for the SRBD-PSQ and OSA-18, respectively). All analyses were performed with Stata software version 15 (Stata Corp. LLC, College Station, TX). 


\section{Results}

Of those who returned a complete SRBD-PSQ $(\mathrm{N}=50)$, mean age of the child at time of completion was $7.1 \pm 4.4$ years. Of these children, $58 \%$ were male and 13 individuals were obese (Table 3.a.). Mean oAHI for the sample was $8.10 \pm 11.3$ events per hour. Average SRBD-PSQ total score was $0.5 \pm 0.2$, which was significantly different from that of published population average scores of $0.3 \pm 0.2(\mathrm{p}<0.05)$. Of the domains within this questionnaire, snoring had the highest average score $(0.6 \pm 0.4)$, while sleepiness had the lowest $(0.4 \pm 0.4)$. The average score in the behavior domain was $0.5 \pm 0.3$. When the sample was stratified by age, there were 20 preschoolers ( $2-3$ years $), 19$ children $(5-11$ years $)$ and 11 were adolescent $(12-18$ years $)$. All groups had a slight male predominance $(65 \%, 53 \%$ and $55 \%$, respectively). The proportion of obese children in each group was $21 \%, 34 \%$ and $33 \%$, respectively. Mean oAHI in preschoolers and children were $6.9 \pm 6.9$ events per hour and $4.4 \pm 3.0$ events per hour, respectively. Average oAHI in adolescents was $17.5 \pm 21.4$ events per hour.

Across all age-ranges, SRBD-PSQ average total score was significantly different from published population averages $[0.4 \pm 0.2,0.5 \pm 0.2$ and $0.5 \pm 0.2$, in preschoolers $(p<0.05)$, children $(\mathrm{p}<0.05)$ and adolescents $(\mathrm{p}<0.05$, respectively)]. Average score for the snoring domain was highest among adolescents $(0.7 \pm 0.3)$. In preschoolers and children, average scores for the snoring domain were $0.6 \pm 0.3$ and $0.6 \pm 0.4$, respectively. Within the sleepiness domain, average score was lowest in preschoolers $(0.2 \pm 0.3)$ and highest in adolescents $(0.6 \pm 0.4)$. The sleepiness domain average score for children was $0.4 \pm 0.4$. The average behavior domain score was as follows for the age-ranges: $0.4 \pm 0.3,0.5 \pm 0.3$ and $0.5 \pm 0.4$, in preschoolers, children and adolescents, respectively) 
Of those who completed the OSA-18 $(\mathrm{N}=36)$, average age of the child at time of completion was $7.7 \pm 4.6$ years. This sample was $61 \%$ male and 6 individuals were obese (Table 3.b.). Mean oAHI for the sample was $8.8 \pm 11.6$ events per hour. OSA-18 average total score was $55.5 \pm 23.0$. Within the OSA-18 domains, emotional distress had the lowest average score (7.7 \pm 4.8$)$ and sleep disturbance had the highest average score $(13.5 \pm 6.7)$. Within this group, there were 13 preschoolers ( $2-3$ years), 14 children ( $5-11$ years) and 9 adolescents $(12-18$ years). Again, each group had a slight male predominance (69\%, 57\% and 56\%, respectively). The proportion of obese children in each group was $17 \%, 18 \%$ and $29 \%$, in preschoolers, children and adolescents, respectively. Mean oAHI was $8.2 \pm 7.6$ events per hour in preschoolers, $4.9 \pm 3.2$ events per hour in children and $16.0 \pm 22.0$ events per hour in adolescents.

OSA-18 mean total score was highest in adolescents $(61.6 \pm 26.2)$ and lowest in children $(49.5 \pm 23.5)$. Preschooler average total score for the OSA-18 was $57.7 \pm 20.0$. Between the five different domains, emotional distress had the lowest average score for preschoolers and children $(7.7 \pm 3.9$ and $6.1 \pm 3.9$, respectively). Daytime function had the lowest average score of all the domains for adolescents $(9.8 \pm 4.0)$ and sleep disturbance had the highest average score $(15.4 \pm$ 5.4). For preschoolers, the highest average score of OSA-18 domains was caregiver concerns $(14.3 \pm 6.3)$ and for children highest average score within the domains was physical symptoms $(12.9 \pm 6.7)$.

A Spearman's correlation analysis was run for the overall cohort and each of the stratified age-ranges to determine the relationship between SRBD-PSQ scores (total and domain scores) and oAHI (Table 4.a.). Overall, there was a weak, positive correlation between SRBD-PSQ total score and oAHI, which was not statistically significant $\left(\mathrm{r}_{\mathrm{s}}=0.23, \mathrm{p}>0.05\right)$. There was also a 
weak, positive correlation between each of the SRBD-PSQ domains and oAHI, which were not statistically significant (sleepiness domain: $\left[r_{s}=0.30, p>0.05\right]$ ). There was a very weak correlation between the snoring domain score and oAHI $\left(\mathrm{r}_{\mathrm{s}}=0.12, \mathrm{p}>0.05\right)$ and almost no correlation between the behavior domain score and oAHI $\left(r_{s}=0.08, p>0.05\right)$.

When stratified by age, SRBD-PSQ total and domain scores were all weakly, positively correlated with oAHI in preschoolers. The behavior domain was the least correlated with oAHI in this age group $\left(\mathrm{r}_{\mathrm{s}}=0.12, \mathrm{p}>0.05\right)$ and the sleepiness domain was most strongly correlated with oAHI $\left(r_{\mathrm{s}}=0.34, \mathrm{p}>0.05\right)$. In children, SRBD-PSQ total score was weakly negatively correlated with oAHI $\left(\mathrm{r}_{\mathrm{s}}=-0.31, \mathrm{p}>0.05\right)$. Additionally, two of the domain scores, snoring and behavior, were weakly negatively correlated with oAHI $\left(r_{s}=-0.47, p>0.05\right.$ and $r_{s}=-0.39, p>$ 0.05, respectively). Adolescents had the strongest correlations between total or domain scores and oAHI. There was a significant, strongly positive correlation between SRBD-PSQ total score and oAHI $\left(\mathrm{r}_{\mathrm{s}}=0.88, \mathrm{p}<0.01\right)$. Additionally, only the adolescent group had a significantly strong, positive correlation between the snoring domain and oAHI $\left(\mathrm{r}_{\mathrm{s}}=0.82, \mathrm{p}<0.05\right)$.

Spearman correlation was also run for all individuals who completed the OSA-18, and for each stratified age-range, to test the correlation between OSA-18 scores (total and domain scores) and oAHI (Table 4.b). Overall, OSA-18 total score was moderately, positively correlated with oAHI $\left(\mathrm{r}_{\mathrm{s}}=0.46, \mathrm{p}<0.05\right)$. There was also a significant moderate, positive correlation between the physical symptoms domain and oAHI $\left(\mathrm{r}_{\mathrm{s}}=0.42, \mathrm{p}<0.05\right)$. The sleep disturbance, emotional distress, daytime function and caregiver concern domains were all weakly, positively correlated with oAHI $\left(\left[\mathrm{r}_{\mathrm{s}}=0.31, \mathrm{p}>0.05\right],\left[\mathrm{r}_{\mathrm{s}}=0.33, \mathrm{p}>0.05\right],\left[\mathrm{r}_{\mathrm{s}}=0.31, \mathrm{p}>0.05\right],\left[\mathrm{r}_{\mathrm{s}}=0.30\right.\right.$ $\mathrm{p}>0.05]$, respectively). 
In preschoolers, OSA-18 total score was moderately, positively correlated with oAHI $\left(\mathrm{r}_{\mathrm{s}}\right.$ $=0.70, \mathrm{p}<0.05)$. All of the domain scores of the OSA-18 were weakly positively correlated with $\mathrm{oAHI}$ in this age group. The emotional distress domain was most weakly correlated with oAHI $\left(r_{s}=0.20, p>0.05\right)$, while the physical symptoms domain was most strongly correlated with oAHI $\left(r_{s}=0.47, p>0.05\right)$. In children all scores (total and domain) were negatively correlated with oAHI (Table 4.b.). Here, the sleep disturbance domain was most strongly negatively correlated with oAHI $(-0.38, p>0.05)$ and the physical symptoms domain was most weakly negatively correlated with oAHI $(-0.08, p>0.05)$. In adolescents, both total and domain scores were all strongly, positively correlated with oAHI (Table 4.b.). Specifically, daytime function and caregiver concerns were most strongly correlated with oAHI $\left(\mathrm{r}_{\mathrm{s}}=0.83, \mathrm{p}<0.05\right.$ and $\mathrm{r}_{\mathrm{s}}=$ $0.83, \mathrm{p}<0.05$, respectively). 


\section{Discussion \& Conclusion}

Our results suggest that, in children with DS, mean scores on the SRBD-PSQ are different from that of published norms from the general pediatric population. OSA-18 total score demonstrated a moderate, positive correlation with oAHI. SRBD-PSQ total score was only weakly, positively correlated with oAHI. However, domain scores within each of these questionnaires showed varying strengths of correlation with oAHI and our results indicate that these questionnaires may function differently across age groups. Specifically, total and domain scores for both the SRBD-PSQ and OSA-18 are strongly correlated with oAHI in adolescents. However, they are not significantly correlated in preschoolers or children. Our analysis revealed an interesting pattern of weak positive correlations between questionnaire scores and oAHI in preschoolers and negative correlations in children. This observation was found across multiple domains, within both the SRBD-PSQ and OSA-18. This suggests that, with a larger sample size, these correlations might achieve significance.

It is unclear why correlations between questionnaire responses and disease severity would be poorer in younger children or why there would be an inverse relationship among children compared to younger and older age groups. We would hypothesize that many of the items on these questionnaires may not accurately reflect the burden of OSA in this population of children. Children with DS commonly have global developmental delays resulting in both behavioral and emotional problems, which could impact responses to the domains addressing this aspect of OSA in unexpected ways. This may be reflected in the finding that the Emotional Distress and Daytime Function domains of the OSA18 had the lowest mean scores, indicating the least impact on quality of life in this population compared to the other domains assessing Sleep Disturbance, Physical Symptoms and Caregiver Concerns. 
The previous work investigating diagnostic accuracy of parent-reported sleep history in children with DS has primarily utilized un-validated symptom screening tools. ${ }^{18-21}$ One study suggested applying the use of a composite predictive model, which included some items from the SRBD-PSQ, in order to rule out moderate or severe OSA in DS patients. ${ }^{22}$ They found that measures from the SRBD-PSQ that were of potential predictive value for OSA belonged to the behavior and snoring domains. This is in line with our findings that the SRBD-PSQ snoring domain was more strongly correlated with oAHI compared to other domains within this questionnaire.

Because OSA occurs frequently in children with DS and polysomnography testing is often costly and uncomfortable or poorly tolerated by these individuals there is a need for alternative assessment of disease burden in this population. With accurate, less burdensome evaluation tools, such as pediatric sleep questionnaires, it may be possible to decrease the need for routine screening via PSG presently recommended by clinical practice guidelines. ${ }^{8}$ The findings of this study suggest that, in children with DS, previously validated pediatric sleep questionnaires may be functioning differently than expected. In particular, the validity of these questionnaires in younger children with DS is questionable. This impacts their applicability and use in both clinical practice and research studies involving children with DS.

However, our study has important limitations. Because it was a retrospective, observational study of patients with available questionnaire and PSG data, there was likely a selection bias. This is because questionnaires were administered to patients referred to the otolaryngology clinic for possible OSA treatment and PSG studies were only ordered based on clinical suspicion of OSA. This may have selected for patients who were strongly symptomatic with a high likelihood of OSA diagnosis. Additionally, this study utilized a convenience sample, 
from our tertiary DS clinic, which may have led to selection bias associated with the collection of the data from a single source. Consequently, these two potential selection biases limit the generalizability of our findings. Prior diagnosis or treatment of OSA could also introduce bias into parental responses to the questionnaires. If parents or caregivers are either more aware of OSA symptoms or expect that these have been addressed with previous treatment, it could alter their responses to specific items. Additionally, it is entirely possible that patients may have received previous treatment that was not accounted for in this analysis.

In summary, for children with DS, the SRBD-PSQ and OSA-18 pediatric sleep questionnaires seem to function as expected in an adolescent age group (ages $12-18$ years) with strong positive correlations with OSA severity, particularly for the OSA-18. However, questionnaire scores were not significantly correlated with OSA severity in younger age groups (ages $2-3$ year and ages $4-11$ years). Further prospective research is needed to investigate their performance, specifically the sensitivity and specificity of these questionnaires in the DS population and across different age-ranges. 


\section{Tables and Figures}

Table 1. Sleep-Related Breathing Disorders Scale of the Pediatric Sleep Questionnaire (SRBD-PSQ)*

\begin{tabular}{llll}
\hline & Yes & No & Don't know \\
\hline
\end{tabular}

While sleeping does your child...

Snore more than half the time?

Always snore?

Snore loudly?

Have "heavy" or loud breathing?

Have trouble breathing or struggle to breathe?

Have you ever...

Seen your child stop breathing during the night?

\section{Does your child....}

Tend to breathe through the mouth during the day?

Have a dry mouth on waking up in the morning?

Occasionally wet the bed?

Wake up feeling un-refreshed in the morning?

Have a problem with sleepiness during the day?

Has a teacher or other supervisor commented that your child appears sleepy during the day?

Is it hard to wake your child up in the morning?

Does your child wake up with headaches in the morning?

Did your child stop growing at a normal rate at any time since birth?

Is your child overweight?

\section{This child often...}

Does not seem to listen when spoken to directly

Has difficulty organizing tasks

Is easily distracted by extraneous stimuli

Fidgets with hands or feet or squirms in seat

Is "on the go" or often acts as if "driven by a motor"

Interrupts or intrudes on others (e.g. butts into conversations or games)

MAXIMUM SCORE: 1

Total score is calculated by dividing the total number of positive responses ("Yes") by the sum of the total number of positive and negative responses ("Yes" + "No").

${ }^{*}$ Reproduced from Appendix A, Chervin et al, Sleep Medicine ${ }^{13}$ 
Table 2. Obstructive Sleep Apnea-18 Quality-of-Life Questionnaire (OSA-18)

\begin{tabular}{lllllll}
\hline $\begin{array}{l}\text { None of } \\
\text { the time }\end{array}$ & $\begin{array}{l}\text { Hardly any } \\
\text { of the time }\end{array}$ & $\begin{array}{l}\text { A little of } \\
\text { the time }\end{array}$ & $\begin{array}{l}\text { Some of } \\
\text { the time }\end{array}$ & $\begin{array}{l}\text { A good bit } \\
\text { of the time }\end{array}$ & $\begin{array}{l}\text { Most of the } \\
\text { time }\end{array}$ & $\begin{array}{l}\text { All of the } \\
\text { time }\end{array}$ \\
\hline 1 & 2 & 3 & 4 & 5 & 6 & 7
\end{tabular}

\section{Sleep Disturbance}

During the past 4 weeks, how often has your child had...

...loud snoring?

...breath holding spells or pauses at night?

...choking or made gasping sounds while asleep?

...restless sleep or frequent awakenings from sleep?

\section{Physical Symptoms}

During the past 4 weeks, how often has your child had...

...mouth breathing because of nasal obstruction?

...frequent colds or upper respiratory infections?

...nasal discharge or a runny nose?

...difficulty in swallowing food?

\section{Emotional Distress}

During the past 4 weeks, how often has your child had...

...mood swings or temper tantrums?

...aggressive or hyperactive behavior?

...discipline problems?

\section{Daytime Function}

During the past 4 weeks, how often has your child had...

...excessive daytime sleepiness?

...a poor attention span or concentration?

...difficulty getting up in the morning?

\section{Caregiver Concerns}

During the past 4 weeks, how often have the problems described above...

...caused you to worry about your child's general health?

...created concern that your child is not getting enough air?

....interfered with your ability to perform daily activities?

...made you frustrated?

MAXIMUM SCORE: 126

Total score is calculated by summing all of the individual item responses.

${ }^{*}$ Reproduced from Table 3, Franco et al, Otolaryngology- Head and Neck Surgery ${ }^{10}$ 
Table 3.a. Descriptive statistics for individuals who had a sleep study within one year of completing the SRBD-PSQ.

\begin{tabular}{|c|c|c|c|c|c|c|c|c|c|}
\hline & \multicolumn{2}{|c|}{$\begin{array}{l}\text { Preschoolers } \\
\text { (2-3 years) }\end{array}$} & \multicolumn{2}{|c|}{$\begin{array}{c}\text { Children } \\
\text { (5-11 years) }\end{array}$} & \multicolumn{2}{|c|}{$\begin{array}{c}\text { Adolescent } \\
(12-18 \text { years })\end{array}$} & \multicolumn{3}{|c|}{ Overall } \\
\hline & $\begin{array}{c}\text { Mean / } \\
\text { No. (\%) }\end{array}$ & $(\mathrm{SD})$ & $\begin{array}{l}\text { Mean / } \\
\text { No. (\%) }\end{array}$ & (SD) & $\begin{array}{l}\text { Mean / } \\
\text { No. (\%) }\end{array}$ & (SD) & $\begin{array}{c}\text { Mean / } \\
\text { No. (\%) }\end{array}$ & (SD) & [Range] \\
\hline Age (years) & 3.27 & $(0.9)$ & 7.15 & $(1.7)$ & 14.36 & (1.5) & 7.19 & $(4.4)$ & {$[2.0,17.4]$} \\
\hline Male & $13(65)$ & & $10(53)$ & & $6(55)$ & & $29(58)$ & & \\
\hline Obese $^{+}$ & $4(21)$ & & $6(34)$ & & $3(33)$ & & $13(30)$ & & \\
\hline oAHI (events/hour) ${ }^{+}$ & 6.93 & $(6.9)$ & 4.35 & $(3.0)$ & 17.45 & $(21.4)$ & 8.10 & (11.3) & {$[0.0,45.6]$} \\
\hline \multicolumn{10}{|l|}{ Domain score } \\
\hline Snoring & 0.55 & $(0.3)$ & 0.56 & $(0.4)$ & 0.69 & $(0.3)$ & 0.58 & $(0.4)$ & {$[0.0,1.0]$} \\
\hline Sleepiness & 0.23 & $(0.3)$ & 0.43 & $(0.4)$ & 0.55 & $(0.4)$ & 0.38 & $(0.4)$ & {$[0.0,1.0]$} \\
\hline Behavior & 0.44 & $(0.3)$ & 0.47 & $(0.3)$ & 0.47 & $(0.3)$ & 0.46 & $(0.3)$ & {$[0.0,1.0]$} \\
\hline Total score ${ }^{\ddagger}$ & $0.43^{*}$ & $(0.2)$ & $0.45^{*}$ & $(0.2)$ & 0.54 * & $(0.2)$ & $0.46^{*}$ & $(0.2)$ & {$[0.0,0.87]$} \\
\hline Children (N) & 20 & & 19 & & 11 & & 50 & & \\
\hline
\end{tabular}

$\mathrm{p}<0.05$.

Note: Analysis was limited to patients with no prior surgery.

+ Some data was missing on one or more participants.

‡Student's t-test was performed to compare mean SRBD-PSQ total score with published norms. 
Table 3.b. Descriptive statistics for individuals who had a sleep study within one year of completing the OSA-18.

\begin{tabular}{|c|c|c|c|c|c|c|c|c|c|}
\hline & \multicolumn{2}{|c|}{$\begin{array}{c}\text { Preschoolers } \\
\text { (2-3 years) }\end{array}$} & \multicolumn{2}{|c|}{$\begin{array}{c}\text { Children } \\
(5-11 \text { years) }\end{array}$} & \multicolumn{2}{|c|}{$\begin{array}{c}\text { Adolescent } \\
(12-18 \text { years }) \\
\end{array}$} & \multicolumn{3}{|c|}{ Overall } \\
\hline & $\begin{array}{l}\text { Mean / } \\
\text { No. (\%) }\end{array}$ & $(\mathrm{SD})$ & $\begin{array}{c}\text { Mean / No. } \\
(\%)\end{array}$ & (SD) & $\begin{array}{l}\text { Mean / } \\
\text { No. (\%) }\end{array}$ & (SD) & $\begin{array}{l}\text { Mean / } \\
\text { No. (\%) }\end{array}$ & (SD) & [Range] \\
\hline Age (years) & 3.42 & $(0.9)$ & 7.25 & $(1.7)$ & 14.63 & $(1.7)$ & 7.71 & $(4.6)$ & {$[2.0,17.4]$} \\
\hline Male & $9(69)$ & & $8(57)$ & & $5(56)$ & & $22(61)$ & & \\
\hline Obese $^{+}$ & $2(17)$ & & $2(18)$ & & $2(29)$ & & $6(20)$ & & \\
\hline oAHI (events/hour) ${ }^{+}$ & 8.15 & $(7.6)$ & 4.86 & $(3.2)$ & 16.00 & $(22.0)$ & 8.78 & $(11.6)$ & {$[0.0,45.6]$} \\
\hline \multicolumn{10}{|l|}{ Domain score } \\
\hline Sleep disturbance & 13.62 & $(7.6)$ & 12.14 & $(6.7)$ & 15.44 & $(5.4)$ & 13.50 & $(6.7)$ & {$[1,28]$} \\
\hline Physical symptoms & 13.69 & $(6.9)$ & 12.86 & $(6.7)$ & 13.89 & $(7.8)$ & 13.42 & $(6.8)$ & {$[3,27]$} \\
\hline Emotional distress & 7.69 & (3.9) & 6.07 & (3.9) & 10.11 & $(7.8)$ & 7.67 & $(4.8)$ & {$[1,18]$} \\
\hline Daytime function & 8.92 & $(5.3)$ & 6.93 & $(4.5)$ & 9.78 & $(4.0)$ & 8.36 & $(4.7)$ & {$[2,19]$} \\
\hline Caregiver concern & 14.31 & $(6.3)$ & 11.50 & $(7.1)$ & 12.33 & $(5.7)$ & 12.72 & $(6.4)$ & {$[2,28]$} \\
\hline Total score & 57.69 & (20.0) & 49.50 & (23.5) & 61.56 & (26.2) & 55.47 & $(22.9)$ & {$[12,98]$} \\
\hline Children (N) & 13 & & 14 & & 9 & & 36 & & \\
\hline
\end{tabular}

$\mathrm{p}<0.05$.

Note: Analysis was limited to patients with no prior surgery.

+ Some data was missing on one or more participants. 
Table 4.a. Correlation ${ }^{\dagger}$ analysis between AHI and SRBD-PSQ scores in those with PSG data within one year.

\begin{tabular}{|c|c|c|c|c|c|c|c|c|c|c|c|c|}
\hline \multirow[b]{2}{*}{ Domain } & \multicolumn{3}{|c|}{$\begin{array}{c}\text { Preschoolers } \\
\text { (2-3 years) }\end{array}$} & \multicolumn{3}{|c|}{$\begin{array}{c}\text { Children } \\
\text { (5-11 years) }\end{array}$} & \multicolumn{3}{|c|}{$\begin{array}{l}\text { Adolescents } \\
\text { (12-18 years) }\end{array}$} & \multicolumn{3}{|c|}{ Overall } \\
\hline & $\mathrm{N}$ & $\mathrm{R}$ & p-value & $\mathrm{N}$ & $\mathrm{R}$ & p-value & $\mathrm{N}$ & $\mathrm{R}$ & $p$-value & $\mathrm{N}$ & $\mathrm{R}$ & $p$-value \\
\hline Snoring & 19 & 0.22 & 0.37 & 14 & -0.47 & 0.09 & 8 & 0.82 & 0.01 & 41 & 0.12 & 0.44 \\
\hline Sleepiness & 18 & 0.34 & 0.17 & 14 & 0.34 & 0.24 & 8 & 0.40 & 0.33 & 40 & 0.30 & 0.06 \\
\hline Behavior & 16 & 0.12 & 0.66 & 14 & -0.39 & 0.17 & 8 & 0.52 & 0.19 & 38 & 0.08 & 0.64 \\
\hline Total score & 19 & 0.28 & 0.25 & 14 & -0.31 & 0.27 & 8 & 0.88 & 0.004 & 41 & 0.23 & 0.14 \\
\hline
\end{tabular}

Note: Analysis was limited to patients with no prior surgery.

tSpearman Correlation 
Table 4.b. Correlation ${ }^{\dagger}$ analysis between AHI and OSA-18 scores in those with PSG data within one year.

\begin{tabular}{|c|c|c|c|c|c|c|c|c|c|c|c|c|}
\hline \multirow[b]{2}{*}{ Domain } & \multicolumn{3}{|c|}{$\begin{array}{c}\text { Preschoolers } \\
\text { (2-3 years) }\end{array}$} & \multicolumn{3}{|c|}{$\begin{array}{c}\text { Children } \\
\text { (5-11 years) }\end{array}$} & \multicolumn{3}{|c|}{$\begin{array}{c}\text { Adolescents } \\
(12-18 \text { years) }\end{array}$} & \multicolumn{3}{|c|}{ Overall } \\
\hline & $\mathrm{N}$ & $\mathrm{R}$ & $p$-value & $\mathrm{N}$ & $\mathrm{R}$ & $p$-value & $\mathrm{N}$ & $\mathrm{R}$ & $p$-value & $\mathrm{N}$ & $\mathrm{R}$ & p-value \\
\hline Sleep disturbance & 13 & 0.45 & 0.12 & 9 & -0.38 & 0.31 & 6 & 0.81 & 0.05 & 28 & 0.31 & 0.11 \\
\hline Physical symptoms & 13 & 0.47 & 0.10 & 9 & -0.08 & 0.83 & 6 & 0.71 & 0.11 & 28 & 0.42 & 0.03 \\
\hline Emotional distress & 13 & 0.20 & 0.51 & 9 & -0.34 & 0.37 & 6 & 0.81 & 0.05 & 28 & 0.33 & 0.08 \\
\hline Daytime function & 13 & 0.36 & 0.22 & 9 & -0.20 & 0.60 & 6 & 0.83 & 0.04 & 28 & 0.31 & 0.11 \\
\hline Caregiver concern & 13 & 0.33 & 0.27 & 9 & -0.24 & 0.54 & 6 & 0.83 & 0.04 & 28 & 0.30 & 0.11 \\
\hline Total score & 13 & 0.70 & 0.01 & 9 & -0.20 & 0.61 & 6 & 0.77 & 0.07 & 28 & 0.46 & 0.01 \\
\hline
\end{tabular}

Note: Analysis was limited to patients with no prior surgery.

tSpearman Correlation 


\section{References}

1. Deak M, Epstein LJ. The History of Polysomnography. Sleep Medicine Clinics. 2009;4(3):313-321.

2. Bodenner KA, Jambhekar SK, Com G, Ward WL. Assessment and treatment of obstructive sleep-disordered breathing. Clin Pediatr (Phila). 2014;53(6):544-548.

3. Lee CF, Lee CH, Hsueh WY, Lin MT, Kang KT. Prevalence of Obstructive Sleep Apnea in Children With Down Syndrome: A Meta-Analysis. J Clin Sleep Med. 2018;14(5):867875.

4. Bixler EO, Vgontzas AN, Lin H-M, et al. Sleep disordered breathing in children in a general population sample: prevalence and risk factors. Sleep. 2009;32(6):731.

5. Hoffmire CA, Magyar CI, Connolly HV, Fernandez ID, van Wijngaarden E. High prevalence of sleep disorders and associated comorbidities in a community sample of children with Down syndrome. J Clin Sleep Med. 2014;10(4):411-419.

6. Lal C, Strange C, Bachman D. Neurocognitive impairment in obstructive sleep apnea. Chest. 2012;141(6):1601-1610.

7. Maris M, Verhulst S, Wojciechowski M, Van de Heyning P, Boudewyns A. Sleep problems and obstructive sleep apnea in children with down syndrome, an overwiew. Int J Pediatr Otorhinolaryngol. 2016;82:12-15.

8. Bull MJ, Committee on G. Health supervision for children with Down syndrome. Pediatrics. 2011;128(2):393-406.

9. Marcus CL, Brooks LJ, Draper KA, et al. Diagnosis and management of childhood obstructive sleep apnea syndrome. Pediatrics. 2012;130(3):576-584.

10. De Luca Canto G, Singh V, Major MP, et al. Diagnostic capability of questionnaires and clinical examinations to assess sleep-disordered breathing in children: a systematic review and meta-analysis. Journal of the American Dental Association. 2014;145(2):165178.

11. Spruyt K, Gozal D. Pediatric sleep questionnaires as diagnostic or epidemiological tools: a review of currently available instruments. Sleep Med Rev. 2011;15(1):19-32.

12. Sanders E, Hill CM, Evans HJ, Tuffrey C. The Development of a Screening Questionnaire for Obstructive Sleep Apnea in Children with Down Syndrome. Front Psychiatry. 2015;6:147.

13. Franco RA, Jr., Rosenfeld RM, Rao M. First place--resident clinical science award 1999. Quality of life for children with obstructive sleep apnea. Otolaryngol Head Neck Surg. 2000;123(1 Pt 1):9-16.

14. Chervin RD, Weatherly RA, Garetz SL, et al. Pediatric sleep questionnaire: prediction of sleep apnea and outcomes. Arch Otolaryngol Head Neck Surg. 2007;133(3):216-222.

15. Chervin RD, Hedger K, Dillon JE, Pituch KJ. Pediatric sleep questionnaire (PSQ): validity and reliability of scales for sleep-disordered breathing, snoring, sleepiness, and behavioral problems. Sleep Med. 2000;1(1):21-32.

16. Bertapelli F, Martin JES-S, Gonçalves EM, de Oliveira Barbeta VJ, Guerra-Júnior G. Growth curves in Down syndrome: Implications for clinical practice. American Journal of Medical Genetics Part A. 2014;164(3):844-847.

17. Kuczmarski RJ, Ogden CL, Guo SS, et al. 2000 CDC Growth Charts for the United States: methods and development. Vital Health Stat 11. 2002(246):1-190. 
18. Friedman NR, Ruiz AG, Gao D, Ingram DG. Accuracy of Parental Perception of Nighttime Breathing in Children with Down Syndrome. Otolaryngol Head Neck Surg. 2017:194599817726286.

19. Nehme J, LaBerge R, Pothos M, et al. Predicting the presence of sleep-disordered breathing in children with Down syndrome. Sleep medicine. 2017;36:104-108.

20. Ng DK, Chan CH, Cheung JM. Children with Down syndrome and OSA do not necessarily snore. Arch Dis Child. 2007;92(11):1047-1048.

21. Shott SR, Amin R, Chini B, Heubi C, Hotze S, Akers R. Obstructive sleep apnea: Should all children with Down syndrome be tested? Arch Otolaryngol Head Neck Surg. 2006;132(4):432-436.

22. Skotko BG, Macklin EA, Muselli M, et al. A predictive model for obstructive sleep apnea and Down syndrome. Am J Med Genet A. 2017;173(4):889-896. 